Orthopäde $2019 \cdot 48: 213-223$

https://doi.org/10.1007/s00132-018-03678-2

Published online: 17 January 2019

(c) The Author(s) 2019

CrossMark

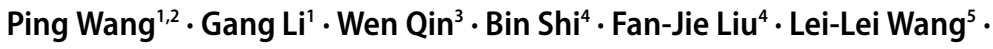 \\ Bo-Nian Zhao ${ }^{2} \cdot$ Tie-feng Sun ${ }^{2} \cdot$ Ling Lin ${ }^{1} \cdot$ Dan-Dan Wang ${ }^{4}$ \\ 'State Key Laboratory of Precision Measurement Technology and Instruments, Tianjin University, Tianjin, \\ China \\ ${ }^{2}$ Shandong Academy of Chinese Medicine, Jinan, China \\ ${ }^{3}$ Shandong University Hospital, Jinan, China \\ ${ }^{4}$ Shandong Medicinal Biotechnology Centre, Shandong Academy of Medical Sciences, Jinan, China \\ ${ }^{5}$ Key Laboratory for Applied Microbiology of Shandong Province, Ecology Institute of Shandong Academy \\ of Sciences, Jinan, China
}

\title{
Repair of osteonecrosis of the femoral head
}

\section{D printed Cervi cornus Colla deproteinized bone scaffolds}

\section{Introduction}

Osteonecrosis of the femoral head $(\mathrm{ONFH})$ is a common refractory joint disease $[1,2]$. Due to its association with high morbidity and disability, ONFH represents a significant financial burden for patients, families and healthcare systems. Multiple possible causes of ONFH include alcohol abuse, HIV infections and organ transplantation $[3,4]$. The prevalent treatment for ONFH is total hip arthroplasty; however, the severe trauma, long recovery period, high medical expense and high risk of side effects associated with this procedure impose a heavy burden on patients, both mentally and physically $[5,6]$. As such, less invasive therapies for the treatment of ONFH are becoming increasingly more popular. The use of $3 \mathrm{D}$ printing, also known as additive manufacturing (AM), refers to processes used to create threedimensional objects in which layers of material are formed under automated control to create an object by adding material layer by layer rather than by subtraction from raw material, as is the case with conventional technologies [7]. The 3D objects can be of almost any geometry and are produced using digital

The authors Ping Wang, Gang Li and Wen Qin contributed equally to the manuscript. model data from a 3D model or another electronic data source, such as an AM file (AMF) [8]. In recent years, 3D printing has become widely known and broadly applied in medical and healthcare fields, such as dentistry, orthopedics and traumatology $[8,9]$. It can facilitate the formation of multiple hierarchical tissue and organ-like structures with high precision, such as small or large bone-like scaffolds with high porosity and microstructure [7]. Moreover, this technology makes patient-specific fabrication and clinical customization achievable [10]. The use of $3 \mathrm{D}$ bioprinting is one of the most effective approaches to fabricate macroscale bone implants with high mechanical strength and controllable microstructures [10]. With the above in mind, advanced 3D printing technology was combined with materials that are known to be conducive to osteoblast proliferation and differentiation with a view to repairing bone defects or osteonecrosis.

Cervi cornus Colla (CCC) is a refined extract from deer antlers, a highly valued traditional Chinese medicine, which has long been considered beneficial for the prevention and treatment of various diseases, such as acute and chronic arthritis, osteoporosis and fractures, as evidenced in animal models and human clinical trials [11-14]. With respect to its chemical composition, CCC is a proteinpolysaccharide complex, which contains 16 amino acids, including glycine, proline and glutamic acid [15]. A previous study revealed that CCC promoted the proliferation and osteogenic differentiation of bone marrow-derived mesenchymal stem cells (BMSC) [16]. In the present study CCC-deproteinized bone scaffolds were designed and $3 \mathrm{D}$ printed for the repair of $\mathrm{ONFH}$ in rats. This research provides support for a new therapeutic approach for the repair of early and midterm ONFH.

\begin{tabular}{|ll}
\hline Abbreviations \\
\hline$A M$ & Additive manufacturing \\
\hline$B M S C$ & $\begin{array}{l}\text { Bone marrow-derived mesenchy- } \\
\text { mal stem cells }\end{array}$ \\
\hline$C C C$ & Cervi cornus Colla \\
\hline DMEM-LG & $\begin{array}{l}\text { Dulbecco's Modified Eagle's } \\
\text { Medium, low glucose }\end{array}$ \\
\hline$H I V$ & Human immunodeficiency virus \\
\hline LSD & Least significant difference test \\
\hline ONFH & Osteonecrosis of the femoral head \\
\hline$P B S$ & Phosphate-buffered saline \\
\hline$R H$ & Relative humidity \\
\hline$S E M$ & Scanning electron microscope \\
\hline
\end{tabular}




\section{Material and methods}

\section{Animals and reagents}

Wistar rats weighing 180-220g (license no. scxk [Lu] 20130009) and 8-day-old Sprague-Dawley rats weighing 25-35g (license no. scxk [Lu] 20130009) were purchased from Shandong University Laboratory Animal Center. The rats were housed in an animal chamber maintained at $22 \pm 2{ }^{\circ} \mathrm{C}$ with a relative humidity $(\mathrm{RH})$ of $50 \pm 5 \%$. The lighting period was maintained at $12 / 12 \mathrm{~h}$ light and dark cycle. Food manufactured by the Laboratory Animal Center of Shandong Province (Jinan, Shandong, China) and tap water were provided ad libitum. All animal experiments were approved by the Institutional Animal Care and Use Committee of The Shandong Academy of Chinese Medicine. Handling of animals strictly followed the ethical guidelines set forth by the European Community guidelines (EEC Directive from 1986; 86/609/EEC).

Deer antler tablets were purchased from Shandong Baiweitang Chinese Herbal Medicine Drinks Slice Co. (Jinan, Shandong, China). Quality management of the deer antler tablets was performed by the Department of Pharmacognosy, Shandong Academy of Chinese Medicine. Quality control was conducted in accordance with the regulations of the Chinese Pharmacopoeia 2015 edition. Fresh adult pig femurs were purchased from the Inzone supermarket (Jinan, Shandong, China). The reagents used in experiments were as follows: $30 \% \mathrm{H}_{2} \mathrm{O}_{2}$, ether, analytical absolute ethanol, $0.25 \%$ trypsin, phosphate buffered saline solution (PBS), trypsinEDTA solution, mixed solution of streptomycin, D-Hank's solution, alizarin red indicator (Solarbio, Beijing, China), Dulbecco's modified Eagle's medium (DMEM-LG), fetal bovine serum (FBS; Hyclone Laboratories, Logan, UT, USA), BCA kit (Beyotime Institute of Biotechnology, Shanghai, China), retinoic acid (production lot number: HL-20151015, Xi'an Huilin Bio-Tech, Shaanxi, China), and the MTT kit (Promega, Madison, WI, USA).

\section{Cervi Cornus Colla preparation}

Colla Cornus Cervi was prepared according to the 2015 edition of Chinese pharmacopoeia [17]. Deer antler tablets were pulverized and mixed with 4-5 times (w/w) distilled water in a round-bottomed flask. The antler tablets were boiled and the extract was removed every $3 \mathrm{~h}$. The distilled water and antler tablet mixture was boiled until the tablets were soft and could be pinched into powder. The extract was collected and concentrated in vacuo (LGJ-10 laboratory freeze dryer, Beijing Songyuan Huaxing Technology Development, Beijing, China) at $50{ }^{\circ} \mathrm{C}$ until the water content was $11 \%$ (w/w \%). The extracts were filtered with double gauze and CCC was obtained after cooling to room temperature. The CCC quality identification and sterilization were conducted as previously described [16].

\section{CCC-deproteinized bone scaffold design and 3D printing}

Cancellous bone was obtained from porcine distal femur chopped into $3 \mathrm{~mm} \times 3 \mathrm{~mm} \times 5 \mathrm{~mm}$ pieces and then submerged in normal saline (NS) for $24 \mathrm{~h}$. After rinsing with distilled water, these pieces were put into a glass bottle with $30 \% \quad \mathrm{H}_{2} \mathrm{O}_{2}$ solution and incubated in a $37{ }^{\circ} \mathrm{C}$ water bath for $48 \mathrm{~h}$. Soxhlet's extraction was used to extract and purify the mixture. The extract was then washed with $75 \%$ ethanol and tridistilled water in a dualfrequency ultrasonic cleaner (Ningbo Scientz Biotechnology, Ningbo, China) three times. The deproteinized bone powder was obtained after freeze drying overnight. The CCC powder and the deproteinized bone powder were mixed (1:10, mass/mass) and micronized. The mixture was filtered through a strainer $(120 \mu$ mesh) and sterilized. A widely used biodegradable material, polycaprolactone (PCL, Seebio Biotech, Shanghai, China), was mixed with the CCC-deproteinized bone powder and used to print the CCC-deproteinized bone scaffolds. Deproteinized bone scaffolds were similarly printed without CCC. All scaffolds were $3 \mathrm{D}$ printed by a fused deposi- tion modelling printer (Qingdao Unique Products Develop Co., Qingdao, China).

\section{Material properties of the scaffolds}

\section{Observation of the scaffolds}

A total of three CCC-deproteinized bone scaffolds were randomly selected for observation under an inverted microscope (Olympus Corporation, Tokyo, Japan). Subsequently, the scaffolds were coated with gold/palladium and observed under a Zeiss SIGMA 300 high resolution field emission scanning electron microscope (Carl Zeiss, Jena, Germany). The pore size of the scaffolds was determined by image analysis software. The porosity of the scaffolds was determined through the improved liquid displacement method. The scaffold was immersed into ethanol (volume V1) in a graduated test tube for $5 \mathrm{~min}$. After negative pressure degasification, the volume of ethanol (immersed with the scaffold) at this time was V2. The scaffold was carefully removed and the residual ethanol volume was V3. The porosity was calculated according to the formula: $(\mathrm{V} 1-\mathrm{V} 3) /(\mathrm{V} 2-\mathrm{V} 3) \times 100 \%$. The experiment was performed in triplicate.

\section{Measurement of mechanical properties}

A total of three scaffoldswere subjected to compression analysis on a Reger universal compression tester (Shenzhen Reger Instrument, Shenzhen, China). Vertical compression tests were used to detect the compression force of the scaffolds. All compression tests were conducted under standard environmental conditions $\left(20 \pm 1{ }^{\circ} \mathrm{C}\right.$, relative humidity, $\mathrm{RH}$ $65 \pm 2 \%)$.

\section{Degradation rate determination}

A total of three scaffolds were randomly selected and weighed (M1). The scaffolds were submerged in $20 \mathrm{ml}$ PBS and incubated in a thermostat (Jintan Medical Equipment Factory, Jiangsu, China) at $37^{\circ} \mathrm{C}$ for 6 weeks. The PBS was replaced every week and the mixture was filtered. The residue was collected and weighed (M2). The weight of the scaffolds (M2-M1) was recorded weekly. 
Hier steht eine Anzeige.

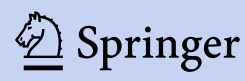


Orthopäde 2019 · 48:213-223 https://doi.org/10.1007/s00132-018-03678-2

(c) The Author(s) 2019

P. Wang · G. Li · W. Qin · B. Shi · F.-J. Liu · L.-L. Wang · B.-N. Zhao · T. Sun · L. Lin · D.-D. Wang

\section{Repair of osteonecrosis of the femoral head. 3D printed Cervi cornus Colla deproteinized bone scaffolds}

\section{Abstract}

Background. Osteonecrosis of the femoral head (ONFH) is a common joint disease and a major cause of morbidity.

Objective. In this study Cervi cornus Colla (CCC) deproteinized bone scaffolds were designed and three dimensional (3D)-printed for the repair of ONFH in rats.

Material and methods. The CCC-deproteinized bone scaffolds were 3D-printed using polycaprolactone mixed with the CCCdeproteinized bone powder. The scaffolds were viewed under a scanning electron microscope and subjected to compression analysis. Osteoblasts were isolated from rats and coated onto the scaffolds. Cell proliferation assays were performed with the MTT (3-[4,5-dimethylthiazole-2]-2,5diphenyltetrazolium bromide) kit from Promega. An ONFH was induced in rats and a CCC-deproteinized bone scaffold was implanted into the necrotic femoral head. General observations, X-ray imaging, and pathological examination of the femoral head were performed to evaluate the treatment of ONFH in the rats.

Results. The scaffolds were porous with a mean pore diameter of $315.70 \pm 41.52 \mathrm{~nm}$ and a porosity of $72.86 \pm 5.45 \%$ and exhibited favorable mechanical properties and degradation. In vitro assays showed that osteoblasts accumulated in the pores and adhered to the scaffolds. The CCCdeproteinized bone scaffolds enhanced the proliferation of osteoblasts. The in vivo experiments revealed that the general observation score of rats in the CCC-scaffold implanted group was significantly higher than that in the control group. The $\mathrm{X}$-ray images showed significant alleviation of ONFH in the CCC-deproteinized bone scaffold implanted rats. The femoral heads of rats in the treatment group showed less destruction or ossification of cartilage cells, few bone cement lines, very little necrosis or irregularities on the cartilage surface and only a small amount of inflammatory cell infiltration in the medullary cavity.

Conclusion. These results suggest that CCC-deproteinized bone scaffold implants facilitated the repair of ONFH in rats. This research provides a new therapeutic approach for the repair of early and mid-term ONFH.

\section{Keywords}

Animal experiments - Traditional Chinese medicine - Morbidity - Polycaprolactone . Osteoblasts

\section{Behandlung einer Osteonekrose des Hüftkopfes. Deproteinisierte Knochengerüste aus Hirschhorngelatine}

\section{Zusammenfassung}

Hintergrund. Die Osteonekrose des Hüftkopfes (ONFH) ist eine häufige Gelenkerkrankung und eine der wichtigsten Ursachen für Morbidität.

Ziel. In dieser Studie wurden deproteinisierte Knochengerüste aus Hirschhorngelatine (Cervi cornus colla, CCC) entwickelt und mittels eines 3-D-Druckers hergestellt, um eine ONFH bei Ratten zu behandeln.

Material und Methoden. Die deproteinisierten CCC-Knochengerüste wurden mittels eines 3-D-Druckers hergestellt unter Verwendung von Polycaprolacton gemischt mit deproteinisiertem CCCKnochenmehl. Die Gerüste wurden unter einem Rasterelektronenmikroskop betrachtet und einer Kompressionsanalyse unterzogen. Osteoblasten wurden aus Ratten isoliert und auf die Gerüste gezogen. ZellproliferationsAssays wurden mittels des MTT-Kits von Promega durchgeführt. Eine ONFH wurde bei
Ratten induziert, und ein deproteinisiertes CCC-Knochengerüst wurde in den nekrotischen Hüftkopf implantiert. Allgemeine Beobachtungen, Röntgenaufnahmen und pathologische Untersuchungen des Hüftkopfes wurden durchgeführt, um die Behandlungen einer ONFH bei Ratten zu evaluieren.

Ergebnisse. Die Gerüste waren porös mit einem mittleren Durchmesser von $315,70 \pm 41,52 \mathrm{~nm}$ und einer Porosität von $72,86 \pm 5,45 \%$. Sie zeigten günstige mechanische Eigenschaften und Degeneration. Invitro-Assays zeigten, dass sich Osteoblasten in den Poren ansammelten und an den Gerüsten anhafteten. Die deproteinisierten CCC-Knochengerüste verbesserten die Proliferation der Osteoblasten. Die In-vivoExperimente zeigten, dass der allgemeine Beobachtungsscore von Ratten in der Gruppe, welcher ein CCC-Knochengerüst implantiert worden war, signifikant höher war als in der Kontrollgruppe. Die Röntgenaufnahmen zeigten eine signifikante Verminderung der ONFH bei Ratten mit einem implantierten CCC-Knochengerüst. Die Hüftköpfe von Ratten in der Behandlungsgruppe zeigten weniger Destruktion oder Ossifikation der Knorpelzellen, wenige Knochenzementlinien und eine sehr geringe Infiltration in der medullären Kavität.

Schlussfolgerung. Diese Ergebnisse zeigen, dass deproteinisierte CCC-Knochengerüstimplantate die Rekonstruktion unterstützen. Diese Studie stellt einen neuen Therapieansatz für die Behandlung einer frühen und mittelfristigen ONFH vor.

Schlüsselwörter

Tierversuche - Traditionelle Chinesische Medizin · Morbidität · Polycaprolacton . Osteoblasten

\section{Osteoblast culture and characterization}

The 8-day-old Wistar rats were killed by cervical dislocation and the skull was harvested. The skull bone was placed in a Petri dish with PBS. The endosteum, pericranium and interosseous tissues were removed. After three washes in PBS, the skull bone was cut into small blocks $\mathrm{f} 1 \mathrm{~mm} \times 1 \mathrm{~mm}$ in size. The bone blocks were digested with $0.25 \%$ trypsin and type II collagenase for $10 \mathrm{~min}$. After discarding the supernatant, the bone blocks were digested with $5 \mathrm{ml}$ type II collagenase for $30 \mathrm{~min}$. After digestion cells were harvested through a cell strainer (100 $\mu$ mesh) and centrifuged (1000 rpm, 


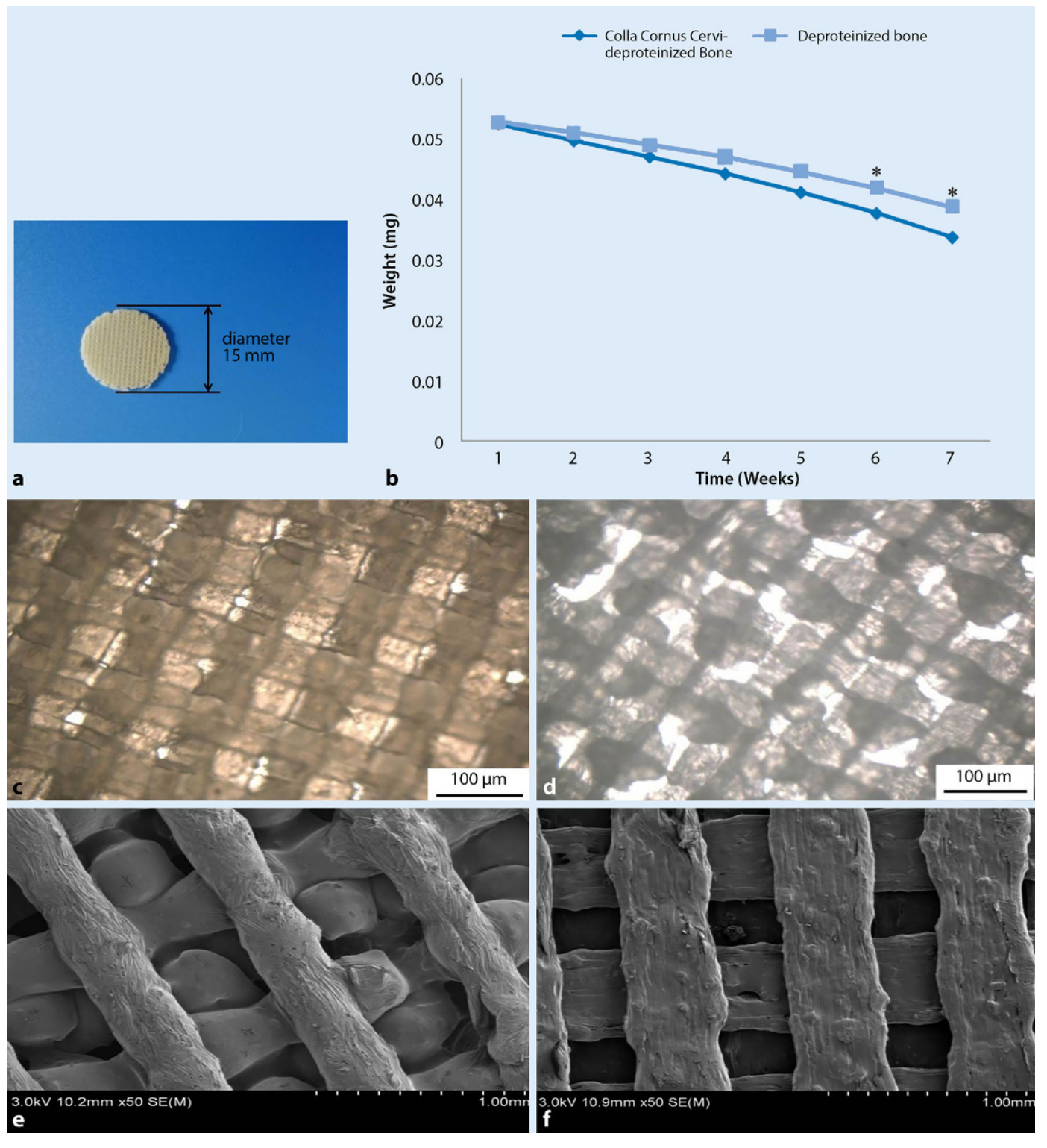

Fig. 1 Scaffold characteristics. a Exterior view of a 3D printed CCC-deproteinized bone scaffold (with a diameter of $15 \mathrm{~mm}$ and a thickness of $3.5 \mathrm{~mm}$ ). b Scaffold degradation curves. The degradation levels of the CCC-deproteinized bone scaffolds and deproteinized bone scaffolds after 6 weeks immersion in PBS reached $35.81 \%$ and $26.61 \%$, respectively $\left({ }^{*} P<0.05\right)$. c CCC-deproteinized bone scaffold observed under microscopy (200× magnification). $\mathbf{d}$ Deproteinized bone scaffold observed under microscopy (200x magnification). e CCC-deproteinized bone scaffold observed under SEM. fDeproteinized bone scaffolds observed under SEM. CCC Cervi cornus Colla, $P B S$ phosphate-buffered saline, SEM scanning electron microscope
$5 \mathrm{~min}$ ). Cells were placed in a $25 \mathrm{~cm}^{2}$ flask and cultured in DMEM-LG supplemented with $20 \%$ FBS in a cell culture incubator (Changsha Hua Xi Electronics Technetronic, Changsha, China) at $37^{\circ} \mathrm{C}$ with $5 \% \mathrm{CO}_{2}$. Culture medium was replaced every 3 days and 8-10 days later, cells were digested with $0.25 \%$ trypsin and subcultured.

The third-generation cells were collected and identified with alizarin red staining. After two washes with PBS, osteoblasts were fixed with $95 \%$ ethanol for $10 \mathrm{~min}$. After three washes with distilled water, the osteoblasts were stained with $0.1 \%$ alizarin red-Tris- $\mathrm{HCl}(\mathrm{pH} 8.3)$ solution at $37^{\circ} \mathrm{C}$ for $30 \mathrm{~min}$.

\section{Proliferation assay}

The adherent osteoblasts were digested with $0.25 \%$ trypsin and prepared for single cell suspension to a final concentration of $2 \times 10^{4}$ cells $/ \mathrm{ml}$. After soaking the scaffold in cultured medium, the scaffold was immersed in $1 \mathrm{ml}$ cell suspension $\left(2 \times 10^{4}\right.$ cells $)$ in a 24 -well plate and cultured in an incubator at $37{ }^{\circ} \mathrm{C}$ with $5 \%$ $\mathrm{CO}_{2}$. An MTT assay kit was used to evaluate the growth rate and relative cell activity, according to the manufacturer's protocol. After incubation for $24 \mathrm{~h}, 48 \mathrm{~h}$, and $72 \mathrm{~h}, 20 \mu \mathrm{l}$ MTT was added to each well and incubated for an additional $4 \mathrm{~h}$. The absorbance at $490 \mathrm{~nm}$ was measured with a microplate reader (Thermo Fisher
Lab system, Waltham, MA, USA). Each experiment was performed in triplicate.

\section{Repair of ONFH by CCC- deproteinized bone scaffold implanting}

After 1 week of acclimatization, 60 Wistar rats weighing 180-220g were randomly distributed into 3 groups: the control group, the ONFH model group and the CCC-deproteinized bone scaffold implanted group. The rats were given $0.14 \mathrm{~g} / \mathrm{kg}$ retinoic acid by oral gavage once per day to induce ONFH. After 8 weeks, 2 rats were selected randomly and killed by cervical dislocation. The bone tissue of the femoral head was collected to as- 
Table 1 Scoring standard of general condition of the femoral head in the rats

\begin{tabular}{|c|c|c|c|}
\hline Investigation items & Index & Specific performance & Score \\
\hline \multirow[t]{4}{*}{ Behavioral function } & \multirow[t]{4}{*}{ Limp } & Nothing & 7 \\
\hline & & Mild & 5 \\
\hline & & Moderate & 3 \\
\hline & & Severe & 0 \\
\hline \multirow[t]{14}{*}{ Joint mobility } & \multirow[t]{4}{*}{ Flexion } & $>70^{\circ}$ & 9 \\
\hline & & $>60^{\circ}$ & 5 \\
\hline & & $>30^{\circ}$ & 2 \\
\hline & & $<30^{\circ}$ & 0 \\
\hline & \multirow[t]{4}{*}{ Abduction } & $>30^{\circ}$ & 4 \\
\hline & & $>15^{\circ}$ & 2 \\
\hline & & $>5^{\circ}$ & 1 \\
\hline & & $<5^{\circ}$ & 0 \\
\hline & \multirow[t]{3}{*}{ Internal rotation } & $>15^{\circ}$ & 2 \\
\hline & & $>5^{\circ}$ & 1 \\
\hline & & $<5^{\circ}$ & 0 \\
\hline & \multirow[t]{3}{*}{ External rotation } & $>15^{\circ}$ & 2 \\
\hline & & $>5^{\circ}$ & 1 \\
\hline & & $<5^{\circ}$ & 0 \\
\hline
\end{tabular}

Table 2 Comparison between CCC-deproteinized bone scaffolds and deproteinized bone scaffolds

\begin{tabular}{|c|c|c|c|c|c|}
\hline Group & $\begin{array}{l}\text { Pore diame- } \\
\text { ter }(\mathbf{n m})\end{array}$ & $\begin{array}{l}\text { Porosity } \\
(\%)\end{array}$ & $\begin{array}{l}\text { Sample } \\
\text { area } \\
\left(\mathrm{nm}^{2}\right)\end{array}$ & $\begin{array}{l}\text { Maximum } \\
\text { load }(N)\end{array}$ & $\begin{array}{l}\text { Compressive } \\
\text { strength } \\
(\mathrm{MPa})\end{array}$ \\
\hline $\begin{array}{l}\text { CCC-deproteinized } \\
\text { bone scaffolds }\end{array}$ & $315.70 \pm 41.52$ & $72.86 \pm 5.45$ & $9.71 \pm 0.45$ & $283.41 \pm 14.97$ & $6.27 \pm 0.96$ \\
\hline $\begin{array}{l}\text { Deproteinized } \\
\text { bone scaffolds }\end{array}$ & $461.30 \pm 25.18$ & $64.80 \pm 3.87$ & $9.06 \pm 0.56$ & $190.57 \pm 15.42$ & $4.45 \pm 1.02$ \\
\hline \multicolumn{6}{|c|}{ CCC Cervi cornus Colla } \\
\hline
\end{tabular}

sess whether treatment with retinoic acid successfully induced ONFH. The rats in the control group served as healthy comparative animals and were not induced ONFH.

The ONFH rats were anesthetized through intraperitoneal injection of $0.3 \%$ pentobarbital sodium $(1 \mathrm{ml} / 100 \mathrm{~g})$. The rats were fixed in the prone position on the operating table and the right lower limbs were abducted $20^{\circ}$. The CCC-deproteinized bone scaffold was implanted into the necrotic femoral head. Under sterile conditions muscles were separated and the femoral head ligament was exposed. The ligament was slowly peeled off to expose the femoral head. The scaffold was placed to ring the femoral head and fixed and then the muscles were sutured. The necrotic femoral head of the left lower extremity did not receive any treatment. After 10 weeks, general observation, X-ray imaging and pathological examination of the femoral head were performed. The general observations and score were conducted according to $\bullet$ Table 1.

\section{Hematoxylin and eosin (HE) staining and analysis}

The femoral heads were fixed in $10 \%$ formaldehyde for $24 \mathrm{~h}$ before proceeding to paraffin embedding. Serial $5-\mu$ longitudinal sections were stained with hematoxylin and eosin for histopathological examination. The tissue sections were deparaffinized with dimethylbenzene and rehydrated with a $100 \%, 95 \%$, $90 \%, 80 \%$ and $70 \%$ series in ethanol. The sections were stained with hematoxylin for $15 \mathrm{~min}$. After 3 washes with distilled water, the sections were differentiated with $0.3 \%$ acid alcohol for $30 \mathrm{~s}$ and rinsed under running tap water for $10 \mathrm{~min}$. The sections were stained with eosin for $2 \mathrm{~min}$ and rinsed under tap water. Finally, the sections were dehydrated with graded ethanol, cleared and evaluated.

According to Mankin's scoring principles [18] the osteonecrosis of femoral head score was calculated as the sum of cartilage structure score and the osteocyte necrosis score. Briefly, the cartilage structure was scored as 0 (normal), 1 (disorder of tissues, and clear structure layers), 2 (disorder of structure layers), and 3 (severe disorder of tissues and structure layers). Osteocyte necrosis was scored as 0 (normal), 1 (hypertrophy and hyperplasia of osteocytes), 2 (deep staining of osteocytes nucleus), 3 (pyknosis of osteocytes and disappearance of nucleus).

\section{Statistical analysis}

All experiments were performed in triplicate. All statistical analyses were performed using the Statistical Package for the Social Sciences, version 17.0 (SPSS, Chicago, IL, USA). Comparisons between groups were analyzed using the least significant difference (LSD) test. Quantitative data are reported as mean \pm standard deviation. A two-sided $p$-value of less than 0.05 was considered statistically significant.

\section{Results}

3D printing of CCC-deproteinized bone scaffolds and deproteinized bone scaffolds

\section{Macroscopic and microscopic scaffold observations}

The 3D printed scaffolds with a diameter of $15 \mathrm{~mm}$ and a thickness of $3.5 \mathrm{~mm}$ were cylindrical, porous, beige in color and had no distinctive odour (- Fig. 1a). There were a large number of regular pores, as observed under light microscopy ( $\bullet$ Fig. 1c, d). The pore structure was smooth and the pores appeared uniform under SEM ( $\bullet$ Fig. 1e, f). The average pore diameter and porosity of CCC-deproteinized bone scaffolds and 

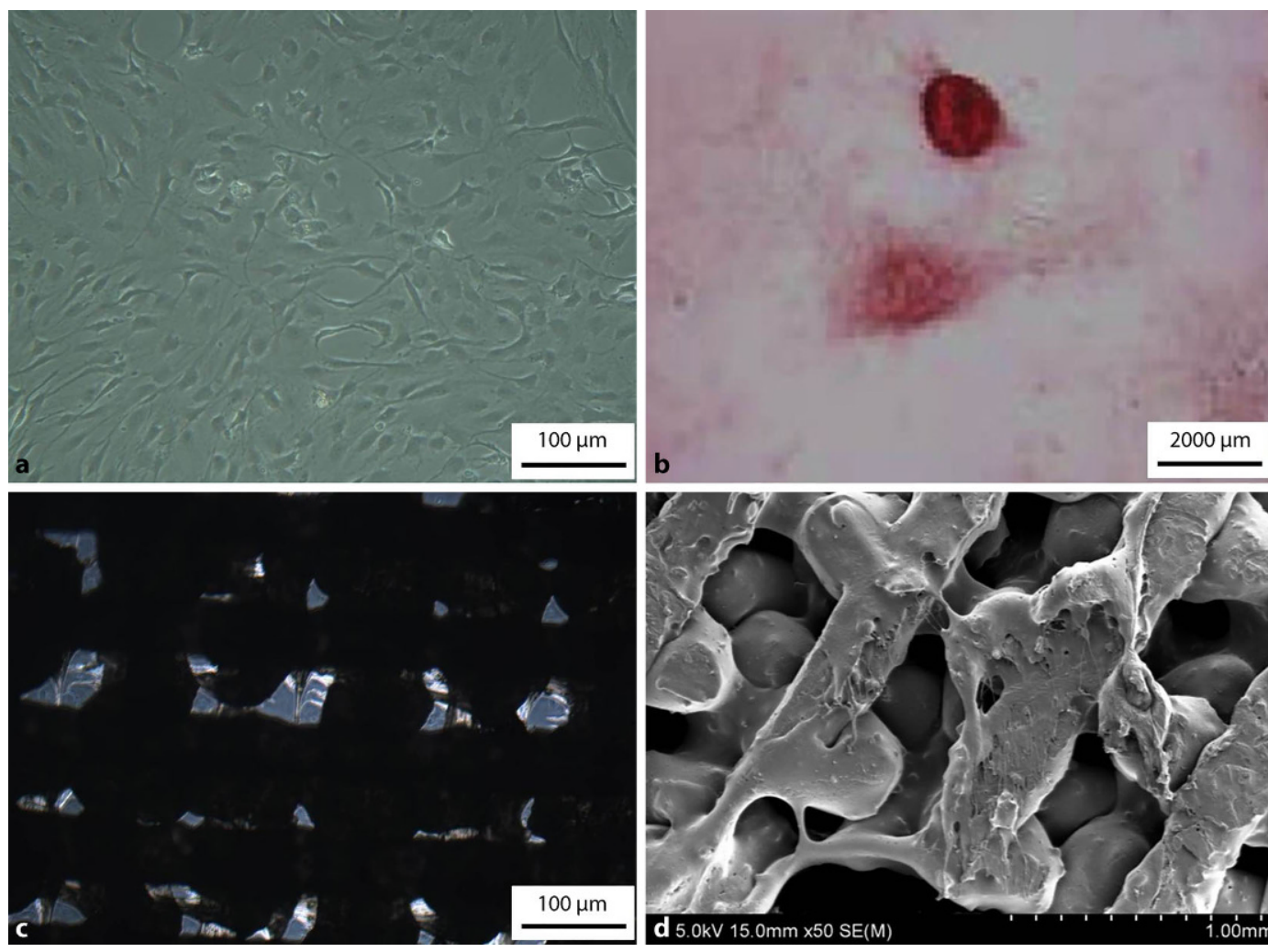

Fig. $2<$ CCC-deproteinized bone scaffolds loaded with osteoblasts. a Osteoblasts cultured in vitro (200× magnification). $\mathbf{b}$ Calcium nodules of the third-generation osteoblasts stained by alizarin red ( $10 \times$ magnification). c Osteoblasts cultivated for $72 \mathrm{~h}$ on the CCC-deproteinized bone scaffolds imaged under light microscopy (200x magnification).d Osteoblasts cultivated for $72 \mathrm{~h}$ on the CCC-deproteinized bone scaffolds imaged under SEM. The cells accumulated in the pores and adhered to the scaffolds. The surfaces of the scaffolds were covered with gelatinous extracellular matrix. CCC Cervi cornus Colla, SEM scanning electron microscope

deproteinized bone scaffolds are shown in - Table 2. The porosity of CCC-deproteinized bone scaffolds $(72.86 \pm 5.45 \%)$ is significantly higher than the deproteinized scaffolds $(64.80 \pm 3.87 \%)$.

\section{Mechanical properties}

Compression tests revealed that with increasing load, the CCC-deproteinized bone scaffolds and deproteinized bone scaffolds were highly compressed. The deproteinized bone scaffolds broke as the compressiveload reached $4.45 \pm 1.02 \mathrm{MPa}$ (- Table 2). The CCC-deproteinized bone scaffolds broke as the compressive load reached 6.27 $\pm 0.96 \mathrm{MPa}$ (• Table 2 ). There was no significant difference in compression properties between the two scaffolds.

\section{Scaffold degradation}

The degradation percentages of the CCCdeproteinized bone scaffolds and deproteinized bone scaffolds after 6 weeks of immersion in PBS were $35.81 \%$ and $26.61 \%$, respectively ( $\bullet$ Fig. 1 b; $P<0.05$ ). The degradation curves are shown in - Fig. 1 b.

\section{Influence of CCC-deproteinized bone scaffolds on the proliferation of osteoblasts}

The results of osteoblast culture and alizarin red staining are detailed in - Fig. $2 \mathbf{a}, \mathbf{b}$. The SEM images revealed that cells accumulated in the pores and adhered to the scaffolds (- Fig. 2c, d). The surface of the scaffold in - Fig. $2 \mathbf{d}$ can be seen covered with gelatinous extracellular matrix. The MTT assays revealed that the proliferation rate of cells cultivated on CCC-deproteinized bone scaffolds was significantly greater than that of the control group (- Table 3 ). These results suggested that CCC-deproteinized bone scaffolds enhanced the proliferation of osteoblasts.

\section{Repair of ONFH using CCC- deproteinized bone scaffolds implanted in rats}

\section{General observations}

The operation and scaffold implanted position in the femoral heads of rats are shown in - Fig. 3a. The rats in the model group showed festering in the tails, limping, and limited joint activity. The rats with implanted CCC-deproteinized bone scaffolds showed no obvious change of femoral head shape, no occurrence of incision infections, and no obvious immunological rejection. The leg activity gradually returned to normal, and none of the rats died. The general observation results were recorded and scored and are detailed in $\bullet$ Table 4 . The results showed that the score of the CCC-deproteinized bone scaffold group was significantly higher than that of the model group (•Table 4, $P<0.001$ ).

\section{X-ray analysis}

The necrotic femoral heads of the ONFH rats showed cystic degeneration and osteosclerosis, and some animals displayed segmental femoral head flattening or subchondral collapse (• Fig. 3c, e). Significant alleviation of femoral head necrosis was observed in the rats implanted with CCC-deproteinized bone scaffolds (- Fig. 3b, d). The X-ray analysis revealed smooth articular surfaces and restoration of necrotic and cystic areas (• Fig. 3d, A), with some rats displaying mild variability in the femoral head, such as mild blurred bone trabecula. 
Table 3 Effect of CCC-deproteinized bone scaffolds on the proliferation of osteoblasts $(\mathrm{X} \pm \mathrm{s}$,

$n=10$ )

\begin{tabular}{|c|c|c|}
\hline \multirow{2}{*}{$\begin{array}{l}\text { Incubation } \\
\text { time (h) }\end{array}$} & \multicolumn{2}{|l|}{ OD $490 \mathrm{~nm}$} \\
\hline & Control group & $\begin{array}{l}\text { CCC-deproteinized bone scaffolds } \\
\text { group }\end{array}$ \\
\hline 24 & $0.247 \pm 0.016$ & $0.492 \pm 0.091^{* *}$ \\
\hline 48 & $0.535 \pm 0.093$ & $0.767 \pm 0.118^{* *}$ \\
\hline 72 & $0.564 \pm 0.047$ & $0.612 \pm 0.131^{*}$ \\
\hline
\end{tabular}

\section{Histopathological analysis}

In the control group, femoral heads displayed normal ultrastructure, with regularly arranged cartilage cells, regular bone cement lines and no degeneration or necrosis of the cartilage surface (• Fig. 3f). In the model group, femoral heads exhibited osteocyte degeneration and necrosis, ossification of the cartilage, sclerosis of the ligament fibers, and inflammatory cell infiltration into the medullary cavity (- Fig. $\mathbf{3 g}$ ). In the implanted group, femoral heads exhibited less destruction or ossification of the cartilage cells, few bone cement lines, very few irregular or necrotic cartilage surface regions, and only a few inflammatory cells infiltrated the medullary cavity (- Fig. 3 h). The results of histological score and analysis are shown in $\bullet$ Table 5 . The histological score of CCC-deproteinized bone scaffolds implanted group $(4.5 \pm 0.81)$ was significantly lower than that of model group $(5.5 \pm 0.5, P<0.01)$. These results suggest that CCC-deproteinized bone scaffold implantation facilitated the repair of $\mathrm{ONFH}$ in rats.

\section{Discussion}

The ONFH is a pathologic process which causes bone cells to die and the femoral head to collapse through the interruption of the blood supply to the femoral bone [4]. Vascularization of large-scale artificial bone tissue grafts is the most significant and critical challenge in the reconstruction of bone defects [19]. A specific approach used to meet this challenge in the treatment of ONFH is to form a model of the collapsed femoral head area under the control of a computer imaging system, to construct a precise $3 \mathrm{D}$ structure, before filling and re- pairing the area of ONFH [8]. During such a reconstructive process, the physical and mechanical properties are evaluated to provide experimental support in clinic aspects $[9,10]$. The patientspecific model plays an important role in choosing the most effective approach and strategy [10]. Since 3D printing has become a vital tool in tissue engineering and medicine, there is an ever-growing need to develop new biomaterials that can be $3 \mathrm{D}$ printed and can emulate the compositional, structural, and functional complexities of human tissues and organs [10].

There are very few reports about 3D printed scaffolds for the treatment of ONFH. Zhu et al. created a gelatine scaffold embedded in uniquely shaped $3 \mathrm{D}$ printed porous titanium parts to treat $\mathrm{ONFH}$ in rats. After hybridization with platelets, the scaffold exhibited a low yet considerable rate of stable, and long-term growth factor release [20]. Lv et al. reported a novel $3 \mathrm{D}$ printed device for the localization and extraction of trabeculae from human femoral heads, providing a method for researching musculoskeletal degenerative diseases and possibly a better clinical understanding of these disorders [21].

In the present study CCC-deproteinized bone scaffolds were designed and $3 \mathrm{D}$ printed with a view to repairing ONFH in rats. A widely applied biodegradable material, PCL, was used to build this scaffold due to its appropriate support strength and favorable cytocompatibility [19]. The CCC-deproteinized bone scaffold was 3D printed with a mixture of CCC powder, deproteinized bone powder, and PCL. The CCC, a refined extract from deer antler, is thought to have bone-invigorating therapeutic effects
[22]. Indeed, CCC has been widely used to nourish kidneys and for bone tonifying in traditional Chinese medicine, such as in the treatment of arthritis, osteoporosis [22], hypercholesterolemia [23], and to heal chronic wounds. The CCC contains mineral elements $(\mathrm{Ca}, \mathrm{Zn}$, and $\mathrm{Pb})$, carbohydrates, polypeptides, proteins, and some special cell growth factors [24-27]. Previous studies revealed that CCC promoted osteoblast proliferation and enhanced osteoblastic differentiation [16]. To take advantage of these favorable properties, in the present study CCC was incorporated into PCLbased $3 \mathrm{D}$ printed scaffolds with a view to promoting osteoblast growth and ONFH repair. Moreover, the bone scaffolds were deproteinized to minimize immunological rejection.

The 3D printed CCC-deproteinized bone scaffolds were porous with a pore diameter of $315.70 \pm 41.52 \mathrm{~nm}$ and a porosity of $72.86 \pm 5.45 \%$, which facilitated good nutrient permeability and good support for the adhesion and proliferation of osteoblasts, as evidenced by the MTT assay. Compression tests revealed that the scaffolds exhibited favorable mechanical properties. As such, the scaffolds should play a favorable support function for long-term in vivo engraftment. Furthermore, the degradation of CCC-deproteinized bone scaffolds and deproteinized bone scaffolds was $35.81 \%$ and $26.61 \%$ after 6 weeks immersion in PBS, respectively. Microscopical observation revealed that osteoblasts accumulated in the pores and adhered to the scaffolds. Moreover, the scaffold surfaces were covered with gelatinous extracellular matrix. These results indicated that the $3 \mathrm{D}$ printed scaffolds were conducive to the expansion of osteoblast numbers. In vitro MTT assays revealed that the proliferation of cells cultivated on CCC-deproteinized bone scaffolds was significantly greater than that of the control group. These results suggest that the incorporation of CCC enhanced the proliferation of osteoblasts.

The CCC-deproteinized bone scaffolds were implanted into the necrotic area of femoral heads to repair ONFH in rats. General observations revealed that rats implanted with CCC-depro- 

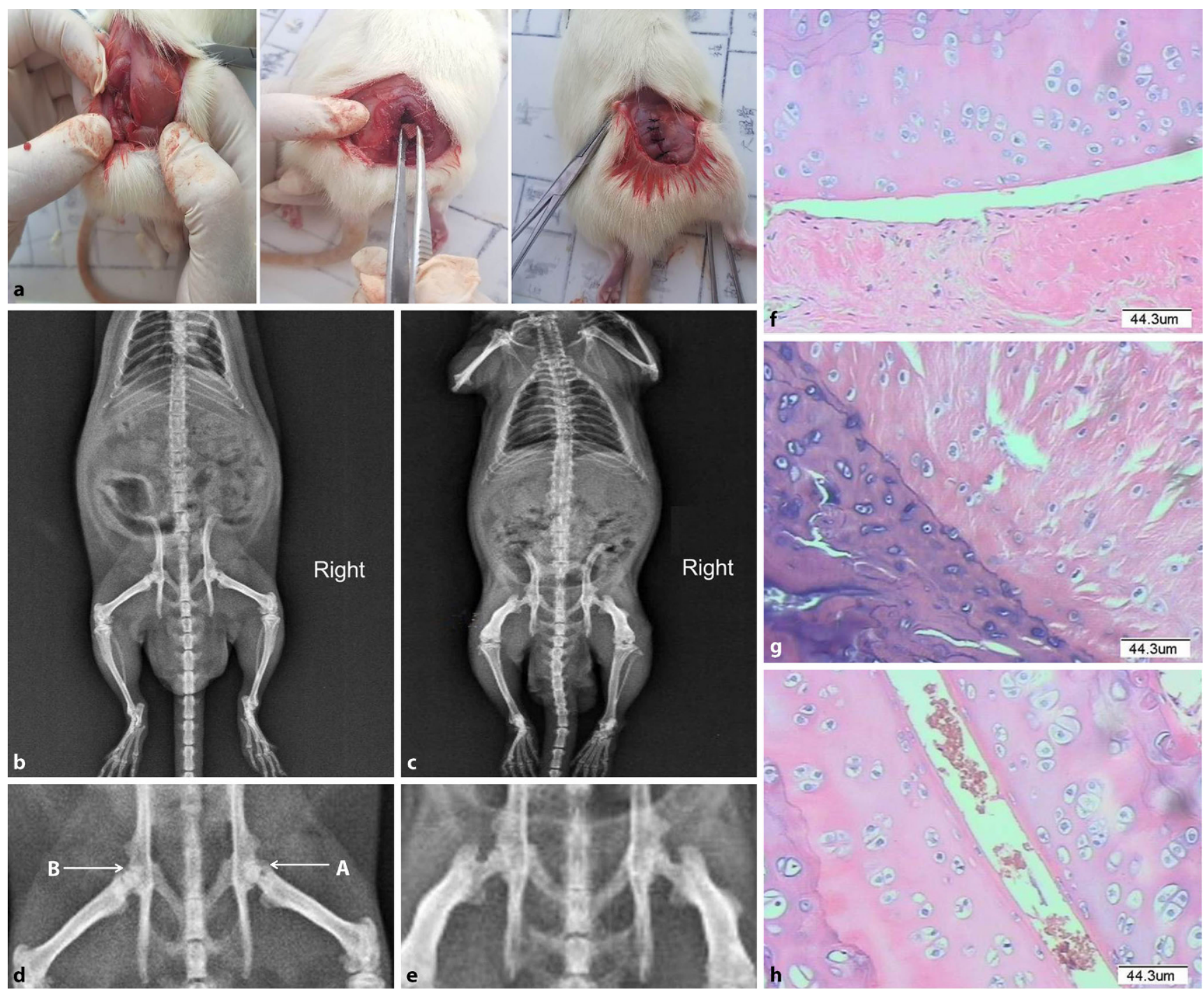

Fig. 3 ॥ Implanted CCC-deproteinized bone scaffolds promoted repair of ONFH in rats. a Operated femoral head of rats showed the operation and scaffold implanted position. $\mathbf{b}$ X-ray image of a prostrate rat implanted with a CCC-deproteinized bone scaffold in the right lower extremity. $\mathbf{C X}$-ray image of an ONFH model rat. $\mathbf{d}$ Corresponding femoral head of the rat implanted with CCC-deproteinized bone scaffold in $\mathbf{b}$ ( $A$ the femoral head implanted with a CCC-deproteinized bone scaffold exhibited a smooth articular surface with restored necrotic and cystic areas. The scaffold is integrated and appears blurred with the surrounding tissues, $B$ the non-implanted femoral head exhibited cystic degeneration, bone fragments, and articular surface collapse). e Corresponding femoral head of the ONFH model rat in c. The necrotic femoral head showed cystic degeneration, osteosclerosis, segmental femoral head flattening and subchondral collapse. f Pathological observation of the femoral head of a rat in the control group (200× magnification). The detailed image reveals normal ultrastructure with regularly arranged cartilage cells, regular bone cement lines, and no degeneration or necrosis of the cartilage surface. g Pathological observation of the femoral head of an ONFH model rat. Results showed osteocyte degeneration and necrosis, ossification of the cartilage, sclerosis of the ligament fibers, and inflammatory cell infiltration in the medullary cavity. h Pathological observation of the femoral head of a rat implanted with a CCC-deproteinized bone scaffold. Less destruction or ossification of cartilage cells, few bone cement lines, very few irregular or necrotic cartilage surface areas, with a small quantity of inflammatory cell infiltration observed in the medullary cavity. CCC Cervi cornus Colla, ONFH Osteonecrosis of the femoral head

teinized bone scaffolds exhibited no obvious change of femoral head shape, no incision infection, and no obvious immunological rejection issues. The general observation score of the implanted group was significantly higher than that of the model group. The X-ray examinations revealed significant alleviation of femoral head necrosis in the rats implanted with CCC-deproteinized bone scaffolds. Histopathological analysis revealed that the femoral heads in the implanted rats showed little destruction or ossification of cartilage cells, few bone cement lines, very few irregularities or necrotic areas on the cartilage surface, with only a small quantity of inflammatory cells infiltrating the medullary cavity. These in vivo results suggest that CCC-deproteinized bone scaffold 
Table 4 The general observation score

of CCC-deproteinized bone scaffolds in the

repair of ONFH in rats $(X \pm s, n=10)$

\section{Group}

Score

Control group

$23.2 \pm 1.32$

Model group

$4.7 \pm 1.16$

CCC-deproteinized bone

$13.1 \pm 1.79^{* * * *}$

scaffolds implanted group

CCC Cervi cornus Colla, ONFHOsteonecrosis

of the femoral head

${ }^{* * * *} P<0.001$, compared with the model group

implants facilitated the repair of ONFH in rats.

For the mechanism study it was reported that angiogenesis provides nutritional support to osteoblast growth and has previously been shown to be a key factor influencing ingrowth of epithelium $[28,29]$. Wang et al. revealed that extract of CCC bone promoted the expression of vascular endothelial growth factor [30]. Previous studies suggested that antler extract had a positive curative effect on avascular necrosis of the femoral head in rats [31]. In the present study, CCC-deproteinized bone scaffold implants facilitated the repair of osteonecrosis. Based on these findings, vascularization may play important roles in the repair of osteonecrosis. In further studies, the effect of CCC-deproteinized bone scaffold on vascularization and molecular mechanisms will be investigated to evaluate the repair of ONFH in rats.

\section{Conclusion}

In the present study CCC-deproteinized bone scaffolds were designed and 3D printed for the repair of ONFH in rats. The scaffolds were porous and exhibited favorable mechanical properties and degradation. In vitro assays showed that CCC-deproteinized bone scaffolds enhanced the proliferation of osteoblasts. In vivo assays with ONFH rats suggested that CCC-deproteinized bone scaffold implants facilitated the repair of ONFH. This research provides a new therapeutic approach for the repair of early and midterm ONFH.
Table 5 Histological score and analysis of CCC-deproteinized bone scaffolds in the repair of ONFH in rats $(X \pm s, n=10)$

\begin{tabular}{ll}
\hline Group & Score \\
\hline Control group & 0 \\
\hline Model group & $5.5 \pm 0.5$ \\
\hline $\begin{array}{l}\text { CCC-deproteinized bone } \\
\text { scaffolds implanted group }\end{array}$ & $4.5 \pm 0.81^{* *}$ \\
\hline $\begin{array}{l}\text { CCC Cervi cornus Colla } \\
{ }^{* *} P<0.01, \text { compared with the model group }\end{array}$ \\
\hline
\end{tabular}

\section{Corresponding address}

\section{Bin Shi}

Shandong Medicinal Biotechnology Centre, Shandong Academy of Medical Sciences 250062 Jinan, China sdyky-shibin@163.com

\section{Ling Lin}

State Key Laboratory of Precision Measurement Technology and Instruments, Tianjin University 300072 Tianjin, China

linling@tju.edu.cn

\section{Dan-Dan Wang}

Shandong Medicinal Biotechnology Centre, Shandong Academy of Medical Sciences 250062 Jinan, China

158wdd@163.com

Funding. This work was supported by the $\mathrm{Na}$ tional Natural Science Foundation of China [grant numbers 81273776 and 31501132], the Major Science and Technology Innovation Projects of Shandong Province (grant numbers 2018CXGC1310 and 2017CXGC1306), the Distinguished Experts of Taishan Scholar Project (grant number ts201511074), the Natural Foundation of Shandong Province (grant number ZR2015HM061), the Shandong Key Research and Development Plan [grant numbers 2016GSF202042 and 2014GSF118026] and the Innovation Project of Shandong Academy of Medical Sciences.

\section{Compliance with ethical guidelines}

Conflict of interest. P. Wang, G. Li, W. Qin, B. Shi, F.-J. Liu, L.-L. Wang, B.-N. Zhao, T.-f. Sun, L. Lin and D.-D. Wang declare that they have no competing interests.

All procedures on animal experimentation reported in this article were in accordance with the ethical standards of the institutional and/or national research committee and with the 1964 Helsinki declaration and its later amendments or comparable ethical standards.

Open Access. This article is distributed under the terms of the Creative Commons Attribution 4.0 International License (http://creativecommons.org/licenses/by/ $4.0 /$ ), which permits unrestricted use, distribution, and reproduction in any medium, provided you give appropriate credit to the original author(s) and the source, provide a link to the Creative Commons license, and indicate if changes were made.

\section{References}

1. Herndon JH, Aufranc OE (1972) Avascular necrosis of the femoral head in the adult. A review of its incidence in a variety of conditions. Clin Orthop Relat Res 86:43-62

2. Zhang C, Zou YL, Ma J, Dang XQ, Wang KZ (2015) Apoptosis associated with Wnt/ $\beta$-catenin pathway leads to steroid-induced avascular necrosis of femoral head. BMCMusculoskelet Disord 16:132

3. Yuan HF, Pan JF, Li S, Guo CA, Liu SH, Yan ZQ (2015) Protective effects of total saponins of panax notoginseng on steroid-induced avascular necrosis of the femoral head in vivo and in vitro. Evid Based Complement Alternat Med. https://doi org/10.1155/2015/165679

4. Martin JR, Houdek MT, Sierra RJ (2013) Use of concentrated bone marrow aspirate and platelet rich plasma during minimally invasive decompression of the femoral head in the treatment of osteonecrosis. Croat Med J 54(3):219-224

5. Osawa Y, Seki T, Morita D, Takegami Y, Okura T, Ishiguro N (2017) Total hip arthroplasty after transtrochanteric rotational osteotomy for osteonecrosis of the femoral head: a mean 10-year follow-up. J Arthroplasty 32(10):3088-3092

6. Hong YC,Zhong HM, LinT, Shi JB (2015)Comparison of core decompression and conservative treatment for avascular necrosis of femoral head at early stage: a meta-analysis. Int J Clin Exp Med 8(4):5207-5216

7. Huang Y, Zhang XF, Gao G, Yonezawa T, Cui X (2017) $3 \mathrm{D}$ bioprinting and the current applications in tissue engineering. Biotechnol J. https://doi.org/ 10.1002/biot.201600734

8. Auricchio F, Marconi S (2017) 3D printing: clinical applications in orthopaedics and traumatology. EFORT Open Rev 1(5):121-127

9. Zhang G, Yu Z, Chen X, Chen X, Wu C, Lin Y et al (2018) Accurate placement of cervical pedicle screws using 3D-printed navigational templates : an improved technique with continuous image registration. Orthopade 47(5):428-436

10. Kim MJ, Lee SR, Lee MY, Sohn JW, Yun HG, Choi $J Y$ et al (2017) Characterization of 3D printing techniques: toward patient specific quality assurance spine-shaped phantom for stereotactic body radiation therapy. PLoSONE 12(5):e176227

11. Yang HO, Kim SH, Cho SH, Kim MG, Seo JY, Park JS et al (2004) Purification and structural determination of hematopoietic stem cellstimulating monoacetyldiglycerides from Cervus nippon (deer antler). Chem Pharm Bull (Tokyo) 52(7):874-878

12. Li C, Zhao H, Liu Z, McMahon C (2014) Deer antler-a novel model for studying organ regeneration in mammals. Int J Biochem Cell Biol 56:111-122

13. Ivankina NF, Isay SV, Busarova NG, Mischenko TY (1993) Prostaglandin-like activity, fatty acid and phospholipid composition of sika deer (Cervus nippon) antlers at different growth stages. Comp Biochem Physiol, B 106(1):159-162

14. Kim J, Jeong HS, Li H, Baek KJ, Kwon NS, Yun HY et al (2013) Effects of Cervi cornus Colla (deer antler glue) in the reconstruction of a skin equivalent model. Arch Dermatol Res 305(1):85-89 
15. Choi HR, Nam KM, Kim DS, Huh CH, Na Jl, Park KC (2013) Cervi cornus Colla (deer antler glue) induce epidermal differentiation in the reconstruction of skin equivalents. Int J Cosmet Sci 35(3):281-285

16. Wang P, Shi B, Gao Z, Sun T, Yang W, Han S et al (2016) Effect of Colla Cornus Cervi combined with LV-mediated BMP7 transfected BMSCs on ANFH in rats. Acta Pol Pharm Drug Res 73(6):1521-1530

17. Chinese Pharmacopoeia Commission (2015) Chinese pharmacopoeia. Part One. The Medicine Science and Technology Press of China, Beijing, p322

18. Moskowitz RW (2006) Osteoarthritis cartilage histopathology: grading and staging. Osteoarthritis Cartilage 14(1):1-2

19. Gao M, Zhang H, Dong W, Bai J, Gao B, Xia $D$ et al (2017) Tissue-engineered trachea from a 3D-printed scaffold enhances whole-segment tracheal repair. Sci Rep 7(1):5246

20. Zhu W, Zhao Y, Ma Q, Wang Y, Wu Z, Weng X (2017) 3D-printed porous titanium changed femoral head repair growth patterns: osteogenesis and vascularisation in porous titanium. J Mater Sci Mater Med 28(4):62

21. Lv $H$, Zhang L, Yang F, Li M, Yin P, Su X et al (2015) A novel 3D-printed device for localization and extraction of trabeculae from human femoral heads: a comparison with traditional visual extraction. Osteoporos Int 26(6):1791-1799

22. Moreau M, Dupuis J, Bonneau NH, Lécuyer M (2004) Clinical evaluation of a powder of quality elk velvet antler for the treatment of osteoarthrosis in dogs. Can Vet J 45(2):133-139

23. Shao MJ, Wang SR, Zhao MJ, Lv XL, Xu H, Li L et al (2012) The effects of velvet antler of deer on cardiac functions of rats with heart failure following myocardial infarction. Evid Based Complement Alternat Med 2012:825056

24. Kardell L, Kallman S (1986) Heavy metals in antlers of roe deer (Capreolus capreolus) from two Swedish forests, 1968-1983. Ambio 15(4):232-235

25. Ko KM, Yip TT, Tsao SW, Kong YC, Fennessy P, Belew MC et al (1986) Epidermal growth factor from deer (Cervus elaphus) submaxillary gland and velvet antler. Gen Comp Endocrinol 63(3):431-440

26. Jhon GJ, Park SY, Han SY, Lee S, Kim Y, Chang YS (1999) Studies of the chemical structure of gangliosides in deer antler, Cervus nippon. Chem Pharm Bull (Tokyo) 47(1):123-127

27. Lu L, Wang K, Li L, Xuan Z, Gong X (2008) Effect of velvet antler polypeptide on peripheral nerve regeneration. Zhongguo Xiu Fu Chong Jian Wai Ke ZaZhi 22(12):1458-1461

28. Herrera P, Caldarone C, Forte V, Campisi P, Holtby H, Chait P et al (2007) The current state of congenital tracheal stenosis. Pediatr Surg Int 23:1033-1044

29. Shin YS, Choi JW, Park JK, Kim YS, Yang SS, Min BH et al (2015) Tissue-engineered tracheal reconstruction using mesenchymal stem cells seeded on a porcine cartilage powder scaffold. Ann Biomed Eng 43:1003-1013

30. Wang Z, Peng H, Li ZH, Zhou YR, Wang ZL (2007) Effect of Cervus and Cucumis polypeptide injection on the rabbits' radius fracture and expression of vascular endothelial growth factor. Med J Wuhan Univ 28:193-199

31. Shi B, Li G, Wang P, Yin W, Sun G, Wu Q et al (2010) Effect of antler extract on corticosteroid-induced avascular necrosis of the femoral head in rats. JEthnopharmacol 127(1):124-129

\section{H. Zeidler, B. A. Michel (Hrsg.) \\ Differenzialdiagnose rheumatischer Erkrankungen}

Der Wegweiser vom Symptom zur Diagnose bei rheumatischen Krankheitsbildern

Berlin/Heidelberg: Springer-Verlag 2019, 5. Auflage,

578 S., 140 Abb., (ISBN: 978-3-662-56574-2),

Hardcover 139,99 EUR, auch als eBook erhältlich

„Die Differenzialdiagnose rheumatischer Erkrankungen ist die Königsdisziplin eines jeden klinisch tätigen Rheumatologen."

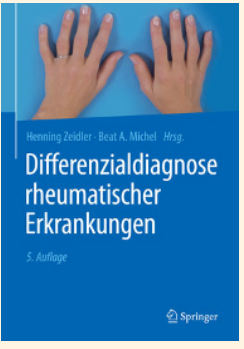

Etabliertes

Lehrbuch neu überarbeit Zur Ausbildung in dieser Kunst und zur Unterstützung im klinischen Alltag wurde das seit vielen Jahrzenten

etablierte Lehrbuch zur Differenzialdiagnose rheumatischer Erkrankungen, welches von Prof. Müller und Prof. Schilling vor vielen Dekaden begründet wurde, von zwei der erfahrensten Rheumatologen, Herrn Prof. Zeidler und Herrn Prof. Michel, komplett neu überarbeitet und jetzt in der 5. Auflage zusammen mit vielen Kollegen herausgegeben.

\section{Prägnant dargestellte} differenzialdiagnostische Parameter

Der Erfolg dieses Buches basiert auf mehreren Alleinstellungsmerkmalen. Dies sind nicht nur die umfassenden Kapitel zu allen Aspekten der differenzialdiagnostischen Herausforderungen, sondern auch die auf über 500 Seiten zu findenden zahlreichen ausführlichen Tabellen und Abbildungen. Hiermit können sowohl die ausführliche Beschreibung als auch die prägnant dargestellten differenzialdiagnostischen Parameter je nach aktuellem Zeitkontingent abgerufen werden.

\section{Feinheiten der körperlichen} Untersuchung und der Blickdiagnose Ein weiteres Alleinstellungsmerkmal, das heutzutage oft vernachlässigt wird, aber gerade bei den schwierigen Problempatienten umso wichtiger ist, sind die mit den eigenen Sinnen eines Arztes untersuchbaren und tastbaren Pathologika des Patienten, sprich die Feinheiten der körperlichen
Untersuchung und der Blickdiagnose. Hier spiegelt sich auch die herausragende lange Erfahrung der Autoren und v.a. der Herausgeber wider, die selbst ja noch nicht mit hochauflösender Bildgebung aufgewachsen sind.

\section{Interdisziplinäre Spezialkapite}

Eine weitere Besonderheit sind Spezialkapitel, unter anderem die rheumatischen Symptome bei verschiedenen nichtrheumatischen Erkrankungen, da die interdisziplinäre Betrachtung eines Patienten aufgrund der Bedeutung des Immunsystems zunehmend in den Vordergrund tritt und der Rheumatologe als Kooperationspartner zahlreicher Disziplinen auch hier sattelfest sein sollte.

Zusammengefasst gehört dieses Standardwerk auf jeden Fall - trotz des allgegenwärtigen Internets - zur essenziellen Handbibliothek des klinisch tätigen Rheumatologen und sollte ruhig schon nach wenigen Wochen deutliche Gebrauchsspuren durch intensives Nachschlagen aufweisen.

Prof. Dr. U. Müller-Ladner (Gießen/Bad Nauheim) 